\section{A CASE OF STRYCHNINE POISONING.}

By G. H. Сооке, M.R.C.S., L.R.C.P.,

LATE hOUSE PHYSICIAN, ROYAL INFIRMART, MANCIIESTER.

THE following case is given merely to show the caution which is necessary in some cases of poisoning. A. M-, male, aged fifty-two, was brought to the infirmary at 11.40 P. M. on August 17th, 1890, stated to have taken sorne poison about half an hour previously. When admitted he was quite rational, face slightly flushed, breath emitted an odour of alcohol, pupils dilated and reacted to light; tongue dry, rest of body fairly moist, limbs lax. Patient gave a history of drink, but denied taking any poison. The stomach was thoroughly washed out with the stomach pump, the fluid withdrawn emitting a strong odour of alcohol. It was afterwards found to contain strychnine by physiological and chemical tests. At 12 midnight, no other symptons being noticed, he was sent to the wards, and at 12.30 A.M. - -i.e., about one hour and a quarter after taking the poisonopisthotonos developed, the face muscles being unaffected. The pulse was 90 , fairly strong, respiration slightly irregular, skin moist, and tongue less dry. Strychnine was diagnosed, and he was given twenty grains each of chloral and potassium bromide; it did not afterwards become necessary to repeat it. The next morning be complained of feeling stiff, but he had sufficiently recovered to be able to leave the infirmary two days after. In the above case, without any history of poison, the cause might bave been overlooked and the patient discharged, for not until fully an hour after it had been taken did any definite symptoms appear, and with a vague history (no specimen of the poison was furnished until later) it is very difficult to separate true from pseudopoisoning cases. In any case it is advisable to wash out the stomach, a proceeding which will do no harm, and may be productive of a great amount of good.

Altrincham.

\section{d.}

oF

\section{HOSPITAL PRACTICE, BRITISH AND FOREIGN.}

Nulla autem est alia pro certo noscendi via, nisi quamplurimas et morborum et dissectionum historias, tum aliorum tum proprias collectas habere, et inter se comparare.-Morgagri De Sed. et Caus. Morb., ib. iv. Proœmium.

\section{PADDINGTON INFIRMARY.}

A CASE OF ELEPHANTIASIS TELANGIECTODES ; ${ }^{1}$ REMARKS.

(Under the care of Dr. THomis SATIL..)

THe short notes of this case which we have given illustrate a condition which, although described by Kaposi and Virchow, is not frequently met with in this country, and is interesting on that account. It is a peculiar form of fibrovascular hypertrophy, which, although probably of congenital origin, does not develop until later in life. It will be noted that in some parts of the subcutaneous tissue there are definite lobulated tumours; in others the growths are more diffused. The vessels in the lobulations are sometimes considerably dilated, and intercommunicate freely.

Ellen E-, aged sixteen, was admitted into the Paddington Infirmary on Dec. 17th, 1889. She was then described as a flabby, unhealthy-looking girl, with a dusky complexion, of small stature, and somewhat deficient in telligence. The right calf is now much larger than the left, measuring one inch more in circumference (14 in. and 13 in respectively). The increase in size is due to a diffused mass, which feels like loose adipose tissue, situated at the back of the leg. The veins of the skin covering it are very apparent, and are here and there collected into little subcutaneous purple patches, which are more obvious after the patient has been walking about much. Sinilar masses of loose vascular adipose tissue are to be found on the outer side of the right knee, the back of the right thigh and the right buttock, and the back of the left thigh.

I The case has been brought before the Irarveinn Society.
There are numerous small venous nævi scattered over the shoulders and elsewhere, varying in size from a small pea to a chestnut, and some small, thin, pigmented moles on the trunk. The only part that is free from any of these three forms of abnormality-viz., subcutaneous thickening, venous nævi, and pigment moles-is the left leg. Mr Hutchinson, who has seen the case, has drawn attention to the fact that some of the bones are enlarged-namely, both tibire and possibly the radii. There is a tendency to genu valgum in the right knee, which the patient declares has only developed during the last few months. The patient's intelligence is not very good, but she declares that she never noticed the lumps on her right leg until about a year ago, when she was fifteen years old. However, Dr. Savill considered it probable that these, like the nevi and pioment marks, and possibly even the enlargement of bones, are all congenital defects, coincident in the same in dividual, increasing, as such defects generally do, with age, and only giving rise to inconvenience when sufficiently advanced. As further illustrations of congenital deficiency in this patient, the mental condition may be mentioned and also the "fits" from which she informs us she suffered all her life until a year ago. These "fits" are preceded by a feeling of giddiness, but no nore information can be procured about them. The lumps in her leg prevent her working at the present time on account of the dull, heavy pain she experiences when walking or standing about. The patient is very subject to bronchitis and sore-throat. The viscera are normal, and the skin condition gives rise to no constitutional symptoms. She was in the Lock Hospital for three months just before admission with gonorrhoa. She believes that her father died of bronchitis and dropsy, and her nother in a confinement, but nothing further is known of her hereditary antecedents.

Remarks by Dr. SAVILL. - The disease is by most anthorities believed to be very closely allied to molluscum fibrosum, and a case of the late Dr. John Murray is referred to by Dr. Liveing, ${ }^{2}$ where the two diseases occurred in the same patient. It is wortlyy of note that in that case, as in this, the intelligence was feeble. No special kind of treatment has been adopted besides rest in the recumbent position and the application of an elastic stocking.

WINTON DISTRICT HOSPITAL, QUEENSLAND. THREE CASES OF HEPATIC DISEASE; REMARKS.

(Under the care of Dr. G. C. MAcDonaLd.)

THE cases of hydatid of the liver are examples of a disease very common in the part of the world in which these patients were treated, especially amongst the dwellers in the Bush, who are dependent upon an impure water-supply. So much is this the rule, that Dr. A. Sennett ${ }^{3}$ of Hamilton states that fully one-third of the necropsies which he had made presented evidence of a cyst, which in most instances had undergone spontaneous cure. In Case 2, the enlarged liver, due to the presence of a cyst, simulated the enlargement secondary to cardiac disease. In Case 1 the chief point of interest is the method employed in passing the sutures and securing the cyst to the abdominal wall. Thomas ${ }^{4}$ gives the statistics of abdominal section for hydatid of the liver as about 90 per cent. of recoveries. The third of these cases is illustrative of a very rare affection indeed-a fistulous communication between a bronchus and a bile-duct. Dr. Macdonald thinks that the disease was of syphilitic origin, and the result of the treatment supports his opinion. Ulceration in to the lung secondary to obstruction of a bileduct by a gall-stone is almost unknown. Murchison met with a fatal case in which gall-stones had escaped into the left pleura.

CASE 1. Hydatid cyst; operation; recovery.-Kcoloured servant, aged thirty, was admitted on April 6th, 1890. She complained of a swelling of the abdomen, of loss of flesh, and general weakness. The patient, from whom it was difficult to obtain any distinct history owing to her imperfect knowledge of English, appeared to have noticed the swelling of the abdomen and general weakness for some months, and dated the former condition from the time she received a kick from one of the coloured men. On

2 Handbook on the Diagnosis of Skin Diseases, p. 275. 1 Bit Med Jour, rol ii, 1880 , p 727 . 
inspection the patient looked generally emaciated, having the peculiar appearance about the face of one suffering from abdominal disease. The abdomen was tumid and distinctly prominent in the right hypochondrium. On palpation, a resistant bulging mass could be distinctly felt in that region, somewhat dome-shaped, and disappearing beneath the ribs. It moved slightly with respiratory rhythm. Percussion revealed that it extended four inches downwards from the free edge of the ribs. There was no so-called hydatid fremitus. Weight $96 \mathrm{lb}$. A hypodermic needle was inserted in the most prominent portion, and a clear fluid (hydatid) evacuated.

April 11th.-She was placed under an anæsthetic, and a linear incision made from the margin of the ribs over the most prominent portion of the tumour vertically downwards for three inches. A solution of perchloride of mercury (1 in 1000) was used for the hands and for wiping the wound; a carbolic acid lotion ( 1 in 40 ) for the instruments. No sponges were used, but balls of sublimated wool. A few bleeding points were caught up and twisted. The muscular wall was much thinned out over the tumour, the peritoneal cavity opened the peritoneum, being nowhere adherent. The trocar was passed into the presenting portion, and a good deal of clear fluid evacuated. Fourstoutsilver wires were passed through the skin and tumour, about half an inch from the free margin of the former. These were brought out at corresponding portions of skin on the other side. An assistant held the wires so as to keep the tumour well against the edge of the wound, which was now incised vertically to correspond to the superficial cut. The centre of the second wire was then taken up, pulled through a sufficient distance, divided, and each end twisted with its corresponding one protruding from the skin. All four were thus treated. 'The abdominal cavity by this means was completely shut off from the cavity of the cyst. Fifty-four ounces of fluid were next evacuated, and 178 daughter cysts counted. Many, however, were lost. The mother cyst came away readily, and presented the usual boiled-egg appearance. The cavity was well washed out with a solution of sublimate, a drainagetube inserted, the wound covered in with sublimated wool pads, and the whole held in place by means of a many. tailed bandage. Her pulse was very weak towards the end of the operation, and half an ounce of brandy was given. She was not permitted to have any thing by the mouth excepting a teaspoonful of milk-and-water at times for the first twenty.four hours, and a quarter of a grain of morphia every four hours.

12th. - The temperature charts showed a rise to $103^{\circ}$ last night; this morning $102^{\circ}$. Complains of very slight pain in the right side, otherwise she is comfortable pulse 120 (not thready). No tenderness on palpation over the abdomen, except just below the wound, and this very slight. Wound looks healthy. Drainage-tube removed and cavity aspirated by means of a rubber tube attached to a glass syringe. About one ounce of blood-stained fluid withdrawn; also three small daughter cysts. Drainage-tube replaced and wound dressed as before.

13th.-Temperature $102^{\circ}$; pulse 110 . Bowels have acted naturally; wound dressed as before.

14th.-Temperature $100^{\circ}$; pulse 100 , full and soft. Tongue moist and clean. No pain or tenderness. Wound looks healthy. About an ounce and a half of fluid evacuated. Dressed as before. To have half a grain of opium instead of the morphia.

15th. - Wound looks healthy; the discharge is sweet, and is becoming less and slightly purulent. Temperature still $100^{\circ}$; pulse 100 . Tongue elean and moist. No tenderness over abdomen. Bowels acted by enema.

22nd.-Two stitches (the lower ones) were removed. There is a small collection of pus beneath the skin, which has probably been the cause of the irregularity of the temperature and the slight tenderness. The first day it was caused by one end of the wire becoming buried in the skin, and thus setting up irritation.

24th.-Remaining sutures removed.

25th-Aspirated fluid from cavity contains several broken down daughter cysts; fluid purulent. Wound dressed as before. Temperature normal. From this date the patient rapidly became convalescent, as shown by weights: May 4th, 80lb. ; 9th, 88 lb. ; 22nd, 94 lb. ; 28th, $96 \mathrm{lb}$. ; June 5 th, $100 \mathrm{lb}$. Discharged cured, the wound being perfectly healed.

CASE 2. Death from morbus cordis; latent hydatid cyst. P. O'L - aged vhirty-eight, dam minder, was admitted on
June 27 th, 1890, complaining of swelling of the legs and shortness of breath. He had had both syphilis and rheumatism. He noticed that for the last two years or longer he became very short of breath on exertion. He has drunk heavily for some years. The veins at the root of the neck are distended and pulsating; heart apex beat displaced to the right; epigastric pulsation ; no thrill ; loud double mitral bruit; pulse feeble, irregular, fluttering, and uncountable; legs anasarcous ; abdomen tumid; ascites present ; liver dulness extends two inches below the free margin of the ribs. It is needless to go into other details, as they are not of interest; suffice it to say that he died suddenly on the morning of July 9 th.

At the post-mortem examination the heart showed the usual signs of mitral stenosis and incompetence, the orifice being narrowed, hard, and the valves nodular, shrunken, and thickened. On the right side the muscular walls were dilated and thinner than normal. There was hæmorrhagicinfarction at the base of the right lung and hypostatic congestion of both lungs. The upper and posterior surface of the right lobe of the liver was partly adherent to the diaphragm, and protruded upward dome-shaped, about the size of a large orange. On removing the organ and the adherent diaphragm and incising the tumour, the cavity of a hydatid cyst was apparent, the size of a man's clenched fist. The cavity was crowded with the usual daughter cysts, there being very little fluid. On examination the kidneys were found to be free from hydatids; but, curiously, they continued their lobulated condition as in fotal life; one kidney had two sets of vessels going to it.

CAse 3. Pulmo-biliary fistula, probably due to syphilis; recovery.-J. R_, aged forty-nine, by trade a butcher, was admitted on April 12th, 1890. He complained of shortness of breath and of cough. About a month previously to admission he commenced to have a dry cough, which lasted about a week. At the end of this period he coughed up "about half a chamberful of matter." This kind of expectoration continued for about fourteen days. When he leaned forward a large amount would come up quite easily. The expectoration became thicker and less in amount. A few days prior to admission the character of the expectoration changed to a dark colour. The patient had been exposed to much privation for the last month, being constantly wet owing to the floods, he being far from any human habitation, and obliged to camp out. He had syphilis in 1864, and malarial fever about five months back, but has not "felt well for two years." Has lost the right eye and the whole of the soft palate from syphilitic ulceration in 1872. General conformation good, but poorly nourished. Both sides of the chest expand equally. On palpation vocal fremitus was normal. No abnormal dulness. There are submucous crepitant râles over the whole of the right lung, more marked towards the base, and some over the posterior lobe of the left. Expectoration frothy and brownish, cough irritable and constant. Liver dulness extends from the nipple line vertically to within one inch of the umbilicus. Bowels regular; appetite good. He was ordered a mixture containing squills, carbonate of ammonia, and compound tincture of camphor, to relieve the cough.

April 20th.-He expectorated to-day a large amount of mucus heavily charged with bile. Cough continues, especially violent at night; the expectoration stains the moustache, beard, and handkerchief a bright yellow. Bile absent from the stools.

27 th. - Expectoration increasing in amount; conjunctivæ show icteric tinge; urine, porter colour. There is slight anasarca of the right foot.

May 1st.-Biliary expectoration has increased if anything, an almost incredible amount of bile thus being got rid of ; most is thrown up about half to one hour after food. The cough keeps both himself and other patients in the ward awake. He was ordered a quarter of a grain of morphia hypodermically at bedtime. Stools still devoid of bile.

20 th. - All expectoration ceased for four days, but it came n again to-day with increased violence.

30 th.-The râles first mentioned have cleared up and the liver dulness is diminishing; stools still white. Believing that the obstruction was due to a syphilitic lesion causing either occlusion of the hepatic duct by ulceration, or more probably a gummatous growth pressing on it, it was decided to put the patient on antisyphilitic treatment, and the following mixture was given : liquor hydrargyri perchloridi, 
one drachm; iodide of potassium, twenty grains ; infusion of calumba, one ounce; to be taken three times a day.

June 7th.- Patient has apparently improved. Cough and biliary expectoration less.

19th. - Cough and biliary expectoration ceased. Bile has now appeared for the first time since the report on April 20th. July 14th.-Patient discharged to-day. Vertical liver dulness in nipple six inches. Lungs by physical examination show nothing abnormal. Abdomen is somewhat tumid, and there is evidently a slight amount of ascites. Ordered to take medicine for two months.

15th.-Presented himself to-day, having had a violent attack of coughing, during which he expectorated three small biliary calculi, two of which were faretted and about the size of a split pea ; the other, about $\frac{1}{3}$ in. long and $\frac{1}{8}$ in. in diameter, formed a perfect coil of a tube (bronchial?). The cough ceased after the foregoing were thrown up. He has since returned to work, feeling well.

Remarks by Dr. MACDONALD. - In Case 2 the hydatid tumour gave no symptoms during life; the slight increase of liver dulness was considered to be due to the backward pressure from the dilated right heart. Its position, comparative size, and "healthy condition" (?) prevented its being diagnosed by either objective or subjective symptoms. In a little while, had the patient not died of heart disease, the cyst would have burst in to the right lung. As regards Case 3 , the diagnosis arrived at, that the symptoms were due to a syphilitic lesion, is, to my mind, not disputable. Obstruction by gall. stones was at one time thought of, but against this theory was the fact that the patient had never suffered from pain or colic of any kind. My idea is that there was a slow-growing gumma in the transverse fissure pressing on the hepatic duct; that the gall-bladder, being distended, formed itself into an abscess cavity, which, pointing upwards, emptied itself into the lung, and thus formed a fistulous communication. The result of treatment was decisive, for he has had no further return of the trouble.

\section{attrical Sorictics.}

\section{PATHOLOGICAL SOCIETY OF LONDON.}

Supposed Indigenous Leprosy.-Pulmonary Gummata.Hepatic Gummata. - Osteit is Deformans. - External Hydrocephalus. - Fibroid Tracheal Polypus._Ectopia Vesice.

AN ordinary meeting of this Society was held on Nov. 4th, the President, Dr. Dickinson, being in the chair.

Dr. HADDEN brought forward a recent specimen of Contracted Stomach, associated with Ulceration of that Viscus and of the Csophagus.

Dr. P. S. AbRahaM read an account of a supposed case of Indigenous Leprosy. In the month of May last paragraphs appeared in the daily newspapers stating that there was a case of undoubted leprosy in Warwickshire. He was requested to visit the case and advise what should be done with the supposed leper, as there was much alarm felt in the neighbourhood. He found the patient, a woman aged sixty-nine, lying in bed in greats pain, and without any proper nursing. The face, body, and limbs were greatly emaciated; the left arm exhibited a large fungating growth at the region of the elbow, above which the arm was much swollen and odematous; the skin of the forearm and hand was thick and brawny, scarred in several plaees, and mottled with dark-brown discolouration. The fingers were flexed, with some of the terminal phalanges gangrenous, and with the nails overgrown and clawlike. The ungual phalanx of the little finger had been spontaneously amputated by ulceration. There was some power of movement of the fingers, and there was no well-marked anæsthesia. The other extremities, and the skin of the rest of the body, showed no spots, patches, or any disease whatever. Every other part but this arm and hand was (and according to the patient has always been) perfectly clear and healthy. She stated that about thirty years ago she noticed a growth "like a bean" on the forearm, the skin becoming scaly and thick around, and this condition gradually extending towards the hand and elbow. The swelling of the limb was comparatively recent, and the cauliflower mass about the elbow had only appeared about two months.
The generrl health had always been good, and family history also. She was born at Coventry, and had never been out of Warwickshire. She was the wife of a labourer, who at one time used to go about the country buying and selling rags and bones. She refused to go into hospital and died a few weeks afterwards. No post-mortem examination was permitted, but Mr. Pitt was kind enough to excise and forward the arm now exhibited, with the drawing taken the next day, and a series of microscopical sections prepared from different parts. No bacilli of leprosy could be found. The sections showed that the tumour at the elbow was a rapidly proliferating epitheliomatoas neoplasm. Within the cell nests, and occupying spaces among the cells outside, were some large protoplasmic masses, reminding one of " psorosperms." Sections from a circumseribed patch on the skin of the arm also indicated epithelioma just commencing, as did those taken from the separated ungual phalanx. In some of these, beneath the epidermic "excrescences," were to be seen giant cells enrrounded by granuloma tissue, as might be observed in lupus. This tended to support Mr. Hutchinson's suggestion that the disease in this case possibly commenced as a superficial lupoid ulceration, scarring over at the spot first attacked and spreading at the edge, and that the epithelioma had been a secondary development. Apart from the pathological interest of the specimens, the case appeared to the author worthy of note from another point of view. It was no doubt in great measure due to the clawed appearance of the hand, the spontaneous loss of one of the phalanges, and the long-continued desquamative condition of the limb that the idea arose of the case being one of leprosy. Had the patient succumbed a few weeks earlier, we should probably have had to quote her in future as a possible case of "indigenous leprosy," and our etio. logical inquiries concerning that disease would be still further confused by another doubtful record.-Dr. CoLCOT'P Fox regarded the specimen as one of chronic tuberculosis followed by epithelioma; it was not like any case of leprosy he had ever sefn or read of. The clinical history was in keeping with tuberculosis, and giant limbs due to repeated attacks of lymphangitis were not rare in cases of lupus of the extremity. Nearly all the cases of indigenous lepross that had been reported were not the true disease; some of them were cases of mycosis fungoides. He doubted, indeed, whether leprosy had ever been indigenous in this country, the greater nuinber of cases sheltered in the lazar houses of old being either lupus or syphilis.-Dr. WILKS had seen two or three cases of indigenous disease which were to him identical with true leprosy. One case was under Addison in Guy's Hospital, and it had been redescribed by Gull, who called it true leprosy. It was the case of a tailor born in Ireland, who came early to London, and who had never been abroad.-Mr. TARGETT proposed that the specimen should be referred to a committee. He found thickening of the ulnar nerve near the wrist. - Mr. WILLIAMS said it was unlike any form of epithelioma he had ever seen; he thought it more resembled granuloma fungoides.--Mr. BRoDIE thought that the microscopic representation demonstrated it to be epithelioma.-The PRESIDENT referred the specimens to a committee consisting of Mr. Cheyne and Dr. Thin and Crookshank.

Dr. ROLLESTON exhibited a specimen of Gumma of the Lung. A section of the organ had been taken near the root. There was considerable induration of the pleura, oneeighth of an inch thick, over the upper and posterior part of the lower lobe, near the root of the lung; there were very firm adhesions at this point. The interlobar septum above the lower lobe was much thickened. The area of lung tissue corresponding to the thickened pleura was markedly fibrosed, and contained a caseous mass, which was somewhat loose. Dr. Délepine kindly supplied a detailed report of the microscopical appearances of the lung. He found chronic interstitial pneumonia and proliferative pleuritis, peribronchitis, chondritis, and perichondritis, with congestion and hæmorrhages, lymphangitis, small granulomata, bronchial stenosis, catarrhal bronchitis, and great inflammation of the glands of the bronchial tubes catarrhal pneumonia, collapse, emphysema, and slight anthracosis. Of all these lesions the most striking were the patches of small lymphoid cells found in the pleura, the interlobular septa, the alveolar walls, and ofter in the alveolar cavities. Some of these patches were distinctly vascular, and differed much in appearance from tubercles. They did not contain bacilli of tubercles 